\title{
Mineração
}

\section{Depressão de minerais de ferro: influência da mineralogia, morfologia e pH de condicionamento}

\author{
Iron ore minerals depression: influence \\ of mineralogy, morphology, \\ and conditioning $\mathrm{pH}$
}

\section{Marisa Martins \\ Doutora em Engenharia Mineral. \\ Departamento de Engenharia de Minas e de \\ Petróleo, Escola Politécnica, \\ Universidade de São Paulo, Brasil. \\ martins.marisa@usp.br}

\section{Neymayer Pereira Lima}

Dsc. Engenheiro de Processo Sênior, Vale, Brasil.

neymayer.lima@vale.com

\section{Laurindo de Salles Leal Filho}

Professor Titular da Escola Politécnica da USP.

Departamento de Engenharia de Minas e de

Petróleo, Escola Politécnica,

Universidade de São Paulo, Brasil.

lauleal@usp.br

\section{Resumo}

Nove amostras de minerais de ferro, provenientes de diferentes minas (jazidas) pertencentes à Vale, foram o objeto desse trabalho, que buscou correlacionar a depressão das referidas amostras com amido e carboximetil celulose versus parâmetros mineralógicos e morfológicos. O amido de milho convencional se mostrou capaz de realizar ação depressora sobre todas as amostras, exceto sobre aquelas que se mostraram mais ricas em hematita compacta (HC). Tais hematitas podem ser chamadas de "problemáticas", visto que interagem fortemente com o coletor e apresentam deficiência de serem deprimidas pelo amido, exigindo elevadas dosagens para minimização de sua tendência à flotação. Carboximetil celulose não apresentou ação depressora sobre nenhuma das amostras estudadas. A flotabilidade das amostras ricas em HC pode ser minimizada pela ação do amido de milho condicionado em $\mathrm{pH}$ 8,0-8,5. Testes de flotação com minério itabirítico, contendo elevado percentual de hematitas compactas de pequeno tamanho de cristal, confirmaram a redução do teor de Fe no rejeito com a utilização de amido condicionado em $\mathrm{pH} \cong 8$.

Palavras-chave: Hematita, amido, flotação, depressão, morfologia.

\begin{abstract}
Nine samples of Fe-bearing minerals from several mines of Vale were the object of this work, which aimed to make a correlation between mineralogy and morphology versus flotation depression by starch and carboxy methyl cellulose. They did not demand strong action from depressants. Cornstarch was able to depress all the samples, except those that exhibited high HC content. The latter samples could be regarded as "problematic" because they were able to interact strongly with collector and demanded a high dosage of depressant to accomplish full depression. Carboxy methylcellulose did not show depressive action on any of the studied $\mathrm{Fe}$ bearing minerals. Flotation response of the samples, which are rich in $\mathrm{HC}$, could be minimized by the action of starch conditioned at $p H$ 8.0-8.5, increasing Fe recovery in the process.
\end{abstract}

Keywords: Hematite, starch, flotation, depression, morphology. 


\section{Introdução}

No âmbito da mineração, flotação é um processo de separação de minerais, que é conduzido em meio aquoso e na presença de bolhas de ar. Nesse processo, partículas que exibem aversão ao meio aquoso (hidrofóbicas) tendem a aderir a bolhas de ar e flutuar. De maneira oposta, partículas que exibem afinidade pela água (hidrofílicas) tendem a afundar. A modulação das propriedades interfaciais dos minerais que compõem um determinado sistema, seja através da indução do caráter hidrofóbico ou reforço do caráter hidrofílico, se dá através do uso de reagentes químicos (coletores, modificadores e espumantes), que, quando bem escolhidos e adequadamente utilizados, permitem a realização de uma separação que atende, tanto aos requisitos de qualidade (teor de elementos-alvo no concentrado produzido), como de quantidade (recuperação mássica e metalúrgica).

Minérios de ferro itabiríticos são compostos, predominantemente, por dois minerais naturalmente hidrofílicos: hematita e quartzo. Para efetuar a separação desses minerais por flotação, consolidou-se, no Brasil, nos últimos 35 anos, uma robusta tecnologia que faz uso de amido, para reforçar o caráter hidrofílico de partículas do mineral hematita, e de surfatantes catiônicos de cadeia longa $\left(\mathrm{C}_{12}-\mathrm{C}_{18}\right)$ para induzir o caráter hidrofóbico nas partículas de quartzo (Brandão, 2005).

O amido é um polímero de alto peso molecular (>300.000 dalton), que é encontrado em vários produtos de origem vegetal (milho, mandioca, batata, trigo, arroz, etc). Ele é formado pela condensação de moléculas de D-glicose, que podem sofrer polimerização linear (amilose, contendo de 200 a 1000 unidades de D-glicose) ou ramificada (amilopectina, contendo mais que 1500 unidades de D-glicose). A matéria ativa do amido de milho, principal depressor utilizado na depressão de óxidos de ferro, é constituída de, aproximadamente, $25 \%$ de amilopectina e $75 \%$ de amilose. Tal matéria ativa encontra-se aprisionada dentro dos grãos de amido e, para que seja liberada, é necessário que o reagente seja submetido a um processo de preparação denominado gelatinização (Araujo et al., 2005; Whistler \& Paschall, 1965).

A gelatinização do amido consiste na destruição da carapaça dos grãos e consequente liberação da matéria ativa (amilose e amilopectina) para a solução. O processo mais utilizado é o da lixiviação com hidróxido de sódio. Nas usinas de concentração, a solução de amido gelatinizado é adicionada a tanques agitados, onde ocorre o condicionamento do reagente com a polpa mineral em pH 10 (Whistler \& Paschall, 1965). Estudos (Raju et al., 1997; Raju et al., 1998) mostraram que o $\mathrm{pH}$ de condicionamento de dextrinas interfere diretamente no grau de adsorção desse depressor sobre diferentes tipos de minerais (fluorita, apatita, galena, magnetita e grafita). Esses estudos mostraram que a máxima adsorção ocorre no $\mathrm{pH}$ no qual a hidroxilação do metal na interface mineral/solução ocorre em maior extensão. No caso da magnetita avaliada nesses estudos, a máxima adsorção de dextrina ocorre na faixa $8,0<\mathrm{pH}<8,5$, na qual existe uma máxima concentração das espécies $\mathrm{Fe}(\mathrm{OH})_{2} \mathrm{e}$ $\mathrm{Fe}(\mathrm{OH})$ na interface magnetita/solução.

Com base nas informações apresentadas nesses estudos, foi avaliada a influência do $\mathrm{pH}$ de condicionamento de amido de milho e de carboximetil celulose sobre a flotabilidade de diferentes tipos de minerais de ferro, provenientes de diferentes usinas de beneficiamento pertencentes à Vale, com o intuito de melhorar a seletividade da separação hematita/ quartzo por flotação.

\section{Materiais e métodos}

\section{Obtenção e preparação das amostras minerais de ferro}

Nove diferentes tipos de amostras de minério de ferro foram utilizadas nesse trabalho. Elas foram previamente classificadas em $0,150 \mathrm{~mm}$, deslamadas e concentradas via flotação catiônica reversa para remoção de quartzo. Após concentração dos minerais de ferro, as amostras foram exaustivamente lavadas com água quente $\left(80^{\circ} \mathrm{C}\right)$ até que sua flotabilidade fosse nula. Tal procedimento foi executado com o intuito de remover os reagentes de flotação que se adsorveram na interface mineral/solução durante o processo de concentração.
A caracterização das amostras foi feita através de análises químicas (fluorescência de raios $\mathrm{X}$ ), granulométricas (peneiramento), mineralógicas e morfológicas (microscopia ótica de luz refletida). As distribuições granulométricas são apresentadas na Tabela 1 , sendo divididas em três frações, de acordo com sua importância no desempenho da flotação (Leal Filho et al., 2006):

i. Fração grossa $(+0,150 \mathrm{~mm})$ : Agregado partícula-bolha é susceptível à destruição por efeito da turbulência existente nas células de flotação, prejudicando o desempenho do processo.

\begin{tabular}{c|c|c|c|c|c|c|c|c|c}
\hline \multirow{2}{*}{$\begin{array}{c}\text { Frações } \\
\text { granulométricas }\end{array}$} & $\mathbf{1}$ & $\mathbf{2}$ & $\mathbf{3}$ & $\mathbf{4}$ & $\mathbf{5}$ & $\mathbf{6}$ & $\mathbf{7}$ & $\mathbf{8}$ & $\mathbf{9}$ \\
\cline { 2 - 11 } & 2,1 & 3,5 & 6,6 & 1,5 & 3,1 & 8,9 & 9,8 & 7,0 & 7,1 \\
\hline$+0,150 \mathrm{~mm}$ & 83,3 & 29,4 & 71,1 & 60,6 & 54,8 & 62,0 & 78,2 & 81,8 & 86,6 \\
\hline$-0,150+0,037 \mathrm{~mm}$ & 14,6 & 67,1 & 22,3 & 37,9 & 42,1 & 29,1 & 12,0 & 11,2 & 6,3 \\
\hline$-0,037 \mathrm{~mm}$ & 100,0 & 100,0 & 100,0 & 100,0 & 100,0 & 100,0 & 100,0 & 100,0 & 100,0 \\
\hline Total & \multicolumn{10}{c|}{}
\end{tabular}

ii. Fração intermediária $(-0,150+$ 0,037mm): Faixa de tamanho ótima visto que a flotação verdadeira (resultado de colisão, adesão e preservação do agregado partícula-bolha) é predominante.

iii. Fração fina $(-0,037 \mathrm{~mm})$ : partículas muito suscetíveis ao arraste hidrodinâmico, o que prejudica a seletividade da separação.

Desse modo, observa-se, na Tabela 1 , que o comportamento das amostras $1,3,6,7,8$ e 9 se presta à avaliação do desempenho dos depressores, visto que todas apresentam conteúdo de finos infe-

Tabela 1

Distribuição granulométrica das amostras. 
rior a $30 \%$. Todavia, o comportamento das amostras 2, 4 e 5, por apresentarem conteúdo de finos superior a $30 \%$, deve ser avaliado com cautela. Uma alta flotabilidade dos minerais de ferro, em tais

Tabela 2

Composição química das amostras.

As análises mineralógicas e morfológicas quantitativas são apresentadas na Tabela 3, assim como o tamanho médio dos cristais dos minerais de ferro presentes nas nove amostras. Conside-

Tabela 3

Análise mineralógica e morfológica das amostras estudadas. amostras, pode não ser devida a uma deficiência de depressão, mas ao arraste das partículas finas para a camada de espuma pelo fluxo ascendente de polpa no interior das células.
A Tabela 2 apresenta a composição química das amostras, atestando que todas elas apresentam nível de pureza semelhante: $65,1 \%<$ teor de $\mathrm{Fe}<69,1 \%$; $0,59 \%<$ teor de $\mathrm{SiO}_{2}<1,47 \%$.

\begin{tabular}{c|c|c|c|c|c|c|c|c|c}
\hline \multirow{2}{*}{ Química (\%) } & \multicolumn{10}{|c}{ Amostra } \\
\cline { 2 - 10 } & $\mathbf{1}$ & $\mathbf{2}$ & $\mathbf{3}$ & $\mathbf{4}$ & $\mathbf{5}$ & $\mathbf{6}$ & $\mathbf{7}$ & $\mathbf{8}$ & $\mathbf{9}$ \\
\hline $\mathrm{Fe}$ & 68,9 & 68,1 & 68,7 & 68,2 & 67,4 & 66,9 & 65,1 & 66,6 & 69,1 \\
\hline $\mathrm{SiO}_{2}$ & 0,82 & 0,86 & 1,30 & 0,77 & 0,97 & 1,47 & 1,05 & 0,90 & 0,59 \\
\hline
\end{tabular}

rando-se que o percentual de hematitas compactas (HC) é o somatório dos tipos $\mathrm{HE}+\mathrm{HL}+\mathrm{HG}+\mathrm{HS}$, foi possível agrupar as amostras em três categorias: $\mathrm{HC}>80 \%$ (amostras 1-3); 60\% $<\mathrm{HC}<80 \%$ (amos- tras 4-6) e $3 \%<\mathrm{HC}<5 \%$ (amostras 7-9). Os resultados das análises morfológicas ainda indicam que as amostras com menores percentuais de $\mathrm{HC}$ apresentaram os maiores tamanhos de cristal.

\begin{tabular}{c|c|c|c|c|c|c|c|c|c|c}
\hline \multirow{2}{*}{ Amostras } & Tamanho dos & \multicolumn{10}{|c}{ Minerais (\% massa) } \\
\cline { 3 - 12 } & cristais ( $\mu \mathbf{m})$ & HE & HL & HG & HS & HC & HM & MA & GO & GT \\
\hline $\mathbf{1}$ & 23,24 & 9,7 & 14,4 & 67,0 & 0,2 & 91,3 & 1,8 & 0,5 & 2,1 & 1,3 \\
\hline $\mathbf{2}$ & 21,06 & 1,9 & 18,8 & 66,6 & 0,2 & 87,5 & 6,3 & 0,4 & 2,9 & 1,5 \\
\hline $\mathbf{3}$ & 36,06 & 7,3 & 16,4 & 74,0 & 0,0 & 97,7 & 0,0 & 0,1 & 0,3 & 0,1 \\
\hline $\mathbf{4}$ & 33,66 & 3,4 & 15,6 & 59,9 & 0,1 & 79,0 & 9,3 & 1,3 & 4,7 & 5,1 \\
\hline $\mathbf{5}$ & 30,12 & 2,6 & 17,9 & 39,9 & 0,0 & 60,4 & 25,0 & 2,3 & 7,4 & 4,0 \\
\hline $\mathbf{6}$ & 43,85 & 1,5 & 10,3 & 58,8 & 0,9 & 71,5 & 15,0 & 4,3 & 5,3 & 2,3 \\
\hline $\mathbf{7}$ & 39,72 & 0,0 & 0,3 & 2,4 & 0,9 & 3,6 & 72,3 & 1,4 & 10,8 & 8,0 \\
\hline $\mathbf{8}$ & 40,96 & 0,0 & 0,4 & 2,9 & 0,5 & 3,8 & 71,3 & 4,8 & 8,5 & 10,7 \\
\hline $\mathbf{9}$ & 38,85 & 0,1 & 0,4 & 0,7 & 4,3 & 5,5 & 29,2 & 58,1 & 3,9 & 2,7 \\
\hline
\end{tabular}

$\mathrm{HE}=$ Hematita especular

$\mathrm{HL}=$ Hematita lamelar

$\mathrm{HG}=$ Hematita granular

$\mathrm{HS}=$ Hematita sinuosa
$\mathrm{HM}=$ Hematita martítica

$\mathrm{MA}=$ Magnetita

$\mathrm{GO}=$ Goethita

GT= Goethita terrosa

\section{Obtenção e preparação da amostra de minério de ferro itabirítico}

Uma amostra de minério de ferro itabirítico do Quadrilátero Ferrífero foi selecionada devido à presença considerável de minerais de ferro com pequeno

Tabela 4

Análises granulométrica e química da amostra de minério de ferro itabirítico.

\section{Medidas de potencial zeta}

Suspensões aquosas $(\mathrm{pH}=10,5)$ preparadas com as amostras 1 a 9 cominuídas abaixo de 500\# $(0,037 \mathrm{~mm})$

\section{Ensaios de flotação}

Ensaios de flotação em escala de bancada foram realizados com as nove amostras minerais, visando a avaliar a tamanho de cristais, ou seja, com elevada afinidade pelo coletor e elevados teores de Fe nos rejeitos, observados industrialmente. Tal minério foi amostrado no circuito

\begin{tabular}{c|c}
\hline Malha (mm) & \% Passante acumulada \\
\hline 0,150 & 95,30 \\
\hline 0,075 & 74,50 \\
\hline 0,045 & 44,00 \\
\hline \multicolumn{2}{|c}{ Análise Química (\%) } \\
\hline $\mathrm{Fe}$ & 61,52 \\
\hline $\mathrm{SiO}_{2}$ & 10,83 \\
\hline
\end{tabular}

foram injetadas no Zetasizer 3000, programado para realizar cinco medidas consecutivas de potencial zeta das par- de processamento após as etapas de moagem e deslamagem. A distribuição granulométrica e os teores de $\mathrm{Fe}$ e $\mathrm{SiO}_{2}$ da amostra são apresentados na Tabela 4. flotabilidade (F) dos minerais de ferro na presença e na ausência de depressores, seguindo as diretrizes apresentadas na Ta- tículas minerais. O resultado final é a média dessas medidas.

bela 5. A flotabilidade foi assumida como sendo a razão entre a massa do produto flotado e a massa da alimentação multi- 
plicada por 100 .

Uma amostra de minério de ferro itabirítico do Quadrilátero Ferrífe- ro também foi submetida a ensaios de flotação em escala de bancada. Tais ensaios foram realizados após coleta

\begin{tabular}{|c|c|}
\hline Objetivos dos Ensaios & Condições Experimentais \\
\hline $\begin{array}{l}\text { Avaliar a flotabilidade } \\
\text { dos minerais de ferro } \\
\text { com éter amina. }\end{array}$ & $\begin{array}{c}\text { Dosagem de éter amina }=230 \text { ou } 460 \mathrm{~g} / \mathrm{t} \\
\mathrm{pH} \text { de flotação=10,4 } \\
\text { Tempo de flotação = Até a exaustão da espuma mineralizada. }\end{array}$ \\
\hline $\begin{array}{c}\text { Estudar a influência dos } \\
\text { depressores amido e CMC, além } \\
\text { do } \mathrm{pH} \text { de condicionamento e o } \\
\text { de flotação na flotabilidade dos } \\
\text { minerais de ferro com éter amina. }\end{array}$ & $\begin{array}{c}\text { Dosagem de amido }=5-500 \mathrm{~g} / \mathrm{t} \\
\text { Dosagem de } \mathrm{CMC}=0,05-500 \mathrm{~g} / \mathrm{t} \\
\text { Dosagem de amina }=230 \text { ou } 460 \mathrm{~g} / \mathrm{t} \\
\mathrm{pH} \text { de condicionamento }=10,5 \text { ou } 8,5 \\
\mathrm{pH} \text { de flotação }=10,5 \text { ou } 8,5\end{array}$ \\
\hline $\begin{array}{l}\text { Estudar a influência da dosagem } \\
\text { e pH de condicionamento do } \\
\text { amido no desempenho da } \\
\text { flotação reversa de um minério } \\
\text { de ferro com éter amina. }\end{array}$ & $\begin{array}{c}\text { Porcentagem de sólidos em massa: } 50 \% \text {. } \\
\text { Dosagem de amina: } 250 \mathrm{~g} / \mathrm{t}_{\mathrm{sio} 2} \\
\text { Dosagem de amido de milho condicionado em pH 10: } 600 \mathrm{~g} / \mathrm{t} \text {. } \\
\text { Dosagem de amido de milho modificado } \\
\text { condicionado em pH 8: } 200,300 \text { e } 450 \text { e } 600 \mathrm{~g} / \mathrm{t} \text {. } \\
\mathrm{pH} \text { de flotação: } 10,5 \text {. }\end{array}$ \\
\hline
\end{tabular}

\section{Resultados e discussão}

\section{Flotabilidade das amostras de minerais de ferro na ausência de depressores}

A flotabilidade, ou resposta à flotação, das nove amostras de minerais de ferro, na presença de coletor (éter amina), $\mathrm{pH}=10,5$, e na ausência de depressor é apresentada na Figura 1, onde se observa que as amostras com maior conteúdo de hematitas compactas (HC), cristais de menor tamanho e menor conteúdo de hematita martitíca, goethitas e magnetita (amostras 1 a 6) foram aquelas que apresentaram a maior flotabilidade na ausência de de- da amostra deslamada industrialmente, seguindo-se as condições apresentadas na Tabela 5.
Tabela 5

Condições experimentais dos ensaios de flotação em bancada.

\section{Máxima Flotabilidade}

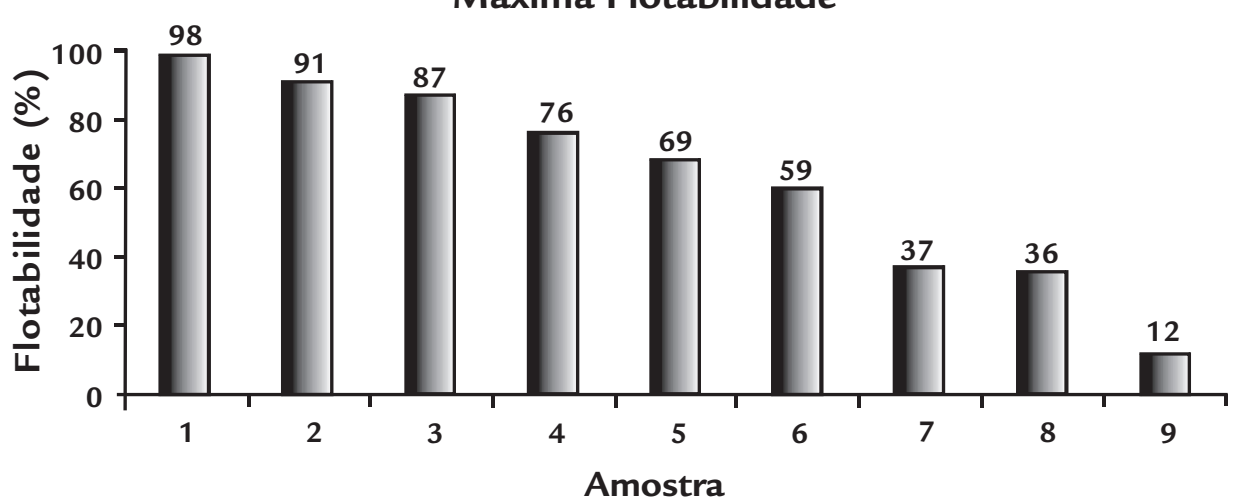

Medindo-se o potencial zeta das partículas das 9 amostras, imersas em meio aquoso $(\mathrm{pH}=10,5)$, obtiveram-se os resultados apresentados na Tabela 6 , onde se observa que:

i. As amostras 7, 8 e 9 são aquelas que apresentam partículas com mais baixo potencial zeta. Além disto, elas são mais pobres em hematita compacta e exibem cristais mais bem desenvolvidos. ii. Embora as amostras 3 e 5 apresentem partículas com potencial zeta (da ordem de $-15 \mathrm{mV})$ e tamanho de cristal $(30-36 \mu \mathrm{m})$ muito semelhante, elas apresentam teor de hematita compacta muito diferente: $60 \%$ para a amostra 5 e $98 \%$ para 3.

iii. Partículas das amostras 1, 2, 4 e 6 foram aquelas que apresentaram potencial zeta mais negativo (de $-20 \mathrm{mV}$ a $-25 \mathrm{mV})$. Para esse grupo em parti- pressor. Tal comportamento sugere que as mesmas demandam uma ação mais efetiva do depressor do que as amostras 7 a 9, que apresentam menores percentuais de hematitas compactas e cristais de maior tamanho.
Figura 1

Máxima flotabilidade das amostras de minerais de ferro na ausência de depressor.

cular, observou-se potencial zeta mais negativo quanto maior o diâmetro dos cristais e menor o teor de hematita compacta.

Com base nesses resultados, é de se esperar que a carga elétrica interfacial das hematitas estudadas, nesse trabalho, seja função, não somente de sua composição química superficial, mas, também, de sua morfologia e mineralogia (teor de hematita compacta).

Tabela 6

Potencial Zeta das amostras minerais de ferro. 
Utilizando ferramenta de análise multivariada (estimativa não linear de Levenberg-Marquardt), disponível no programa Statistica, para um nível de con-

Através da Equação 1, é possível verificar que as variáveis $\mathrm{D}$ (diâmetro dos cristais) e H (\% de HC) são aquelas que apresentam expoentes de maior fiança de $95 \%$ e coeficiente de correlação $\mathrm{r}^{2}=0,9512$, a flotabilidade das amostras (variável dependente) foi correlacionada, através da Equação 1, com as seguintes

$$
F=130,9 H^{0,37} D^{-0,44} Z^{-0,17} f^{0,04}
$$

módulo e, por isso, são aquelas que mais influenciam na flotabilidade das amostras. A magnitude do potencial zeta e a \% de finos $(-0,045 \mathrm{~mm})$ apre- variáveis independentes: $\mathrm{H}(\%$ de hematita compacta), D (diâmetro médio dos cristais), Z (magnitude do potencial zeta em $\mathrm{pH}=10,5)$ e $\mathrm{f}(\%$ de partículas finas).

sentaram pouca influência na flotabilidade dos minerais de ferro na ausência de depressor.

\section{Influência dos depressores amido e CMC na flotabilidade das amostras minerais}

A flotabilidade das amostras 1-9, em função da dosagem de amido, utilizando-se a dosagem de coletor, para se produzir a máxima resposta à flotação, é apresentada na Figura 2. Verificou-se que as amostras 1-3 (maiores \% de HC e com menor tamanho de cristais) foram aquelas que apresentaram maior dificuldade de serem deprimidas pela ação do amido, mesmo em dosagens tão altas quanto
$500 \mathrm{~g} / \mathrm{t}$. Por outro lado, as amostras 7-9, com maiores percentuais de goethita, hematita martítica e magnetita, foram mais efetivamente deprimidas em dosagens de amido muito inferiores $(50 \mathrm{~g} / \mathrm{t})$.
Figura 2

Flotabilidade $x$ dosagem de amido de milho condicionado em $\mathrm{pH}$ 10,5.

Com relação ao desempenho da flotabilidade dos minerais de ferro, em função do $\mathrm{pH}$ de condicionamento com amido (Figura 3), verificou-se que, em $\mathrm{pH}$ ligeiramente básico $(\mathrm{pH}=8,5), \mathrm{o}$ amido foi capaz de deprimir todas as amostras, independentemente do teor de hematitas compactas ou do tamanho dos cristais. Tal comportamento pode ser explicado através de experimentos

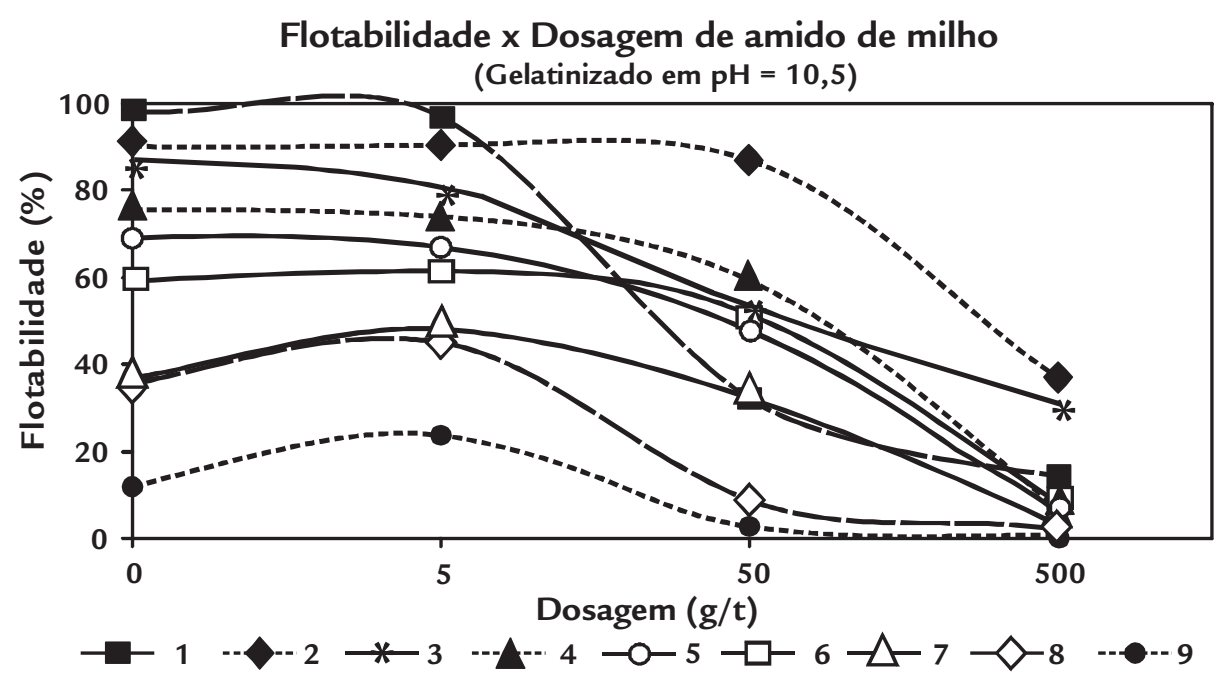

de adsorção realizados por Raju e colaboradores (1997;1998). Nos referidos experimentos, em tal $\mathrm{pH}$, ocorre maior abundância de espécies $\mathrm{Fe}(\mathrm{OH})$ e $\mathrm{Fe}(\mathrm{OH})_{2}$ na interface minerais de ferro/solução. A presença de sítios metálicos hidroxilados, na interface mineral/ solução, favorece a interação química entre o amido e os minerais de ferro, propiciando uma depressão mais efeti- va dos referidos minerais.

A Figura 4 exibe a influência da dosagem de carboximetil celulose (CMC) na depressão das nove amostras de minério de ferro, que constituem o objeto desse trabalho. Variando-se a dosagem de CMC entre $0,05 \mathrm{~g} / \mathrm{t}$ e 500 $\mathrm{g} / \mathrm{t}$, verificou-se que tal reagente não apresentou ação depressora sobre os minerais de ferro.

\section{Flotabilidade $\mathrm{x} \mathrm{pH}$ de condicionamento do amido de milho}

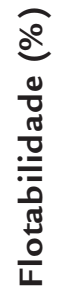

$\left.\begin{array}{cc}\stackrel{0}{0} & 40 \\ \frac{0}{0} & 30 \\ \frac{\pi}{0} & 20 \\ \frac{0}{0} & 10 \\ \frac{\pi}{0} & 10 \\ \frac{0}{4} & 0\end{array}\right]$

Figura 3

Flotabilidade $\mathrm{p} \mathrm{pH}$ de condicionamento de amido de milho.

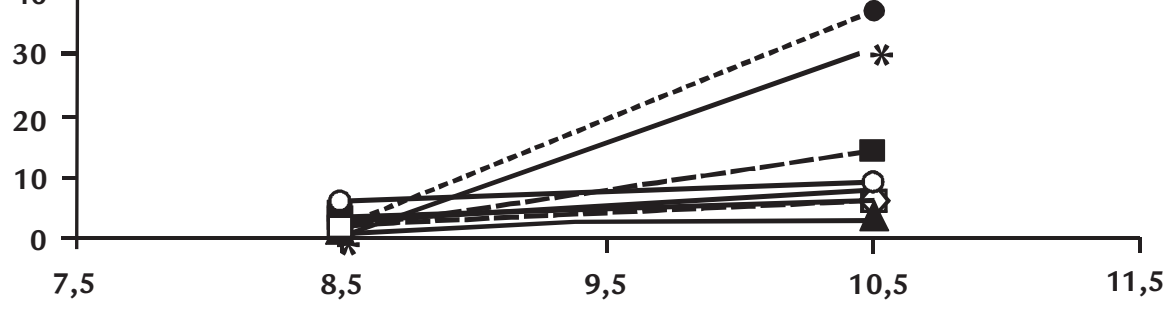

$\mathrm{pH}$ de condicionamento 
Flotabilidade $x$ Dosagem de CMC (Condicionamento em $\mathrm{pH}=10,5$ )

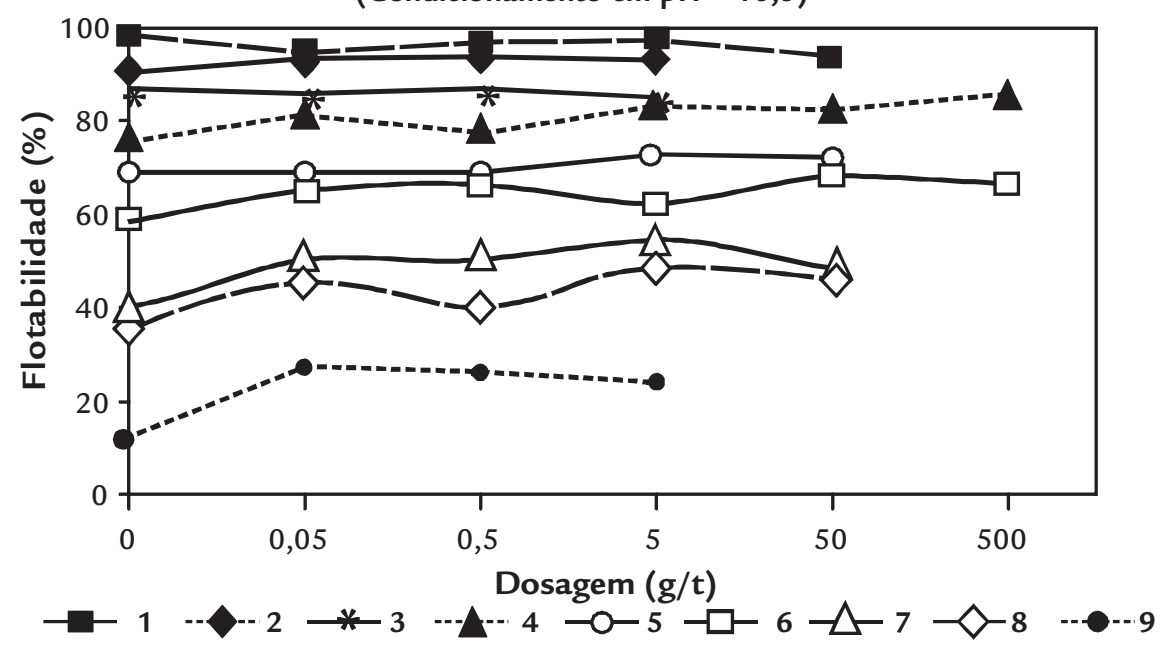

\section{Influência da dosagem e pH de condicionamento do amido no desempenho da flotação do minério de ferro itabirítico}

Os resultados dos ensaios de flotação realizados com a amostra de minério de ferro itabirítico, em termos de recuperação metálica de $\mathrm{Fe}$ e de teor de $\mathrm{SiO}_{2}$ no concentrado, variando-se a dosagem de amido $(200,300,450$ e $600 \mathrm{~g} / \mathrm{t})$ e $\mathrm{pH}$ de condicionamento $(7,7 \times 10,3)$, são apresentados na Figura 5.

Observa-se, na Figura 5, um elevado aumento de recuperação metálica do ferro com a utilização do amido de milho modificado condicionado em $\mathrm{pH}$ próxi-
Figura 4

Flotabilidade $x$ dosagem de CMC condicionado em $\mathrm{pH}$ 10,5.

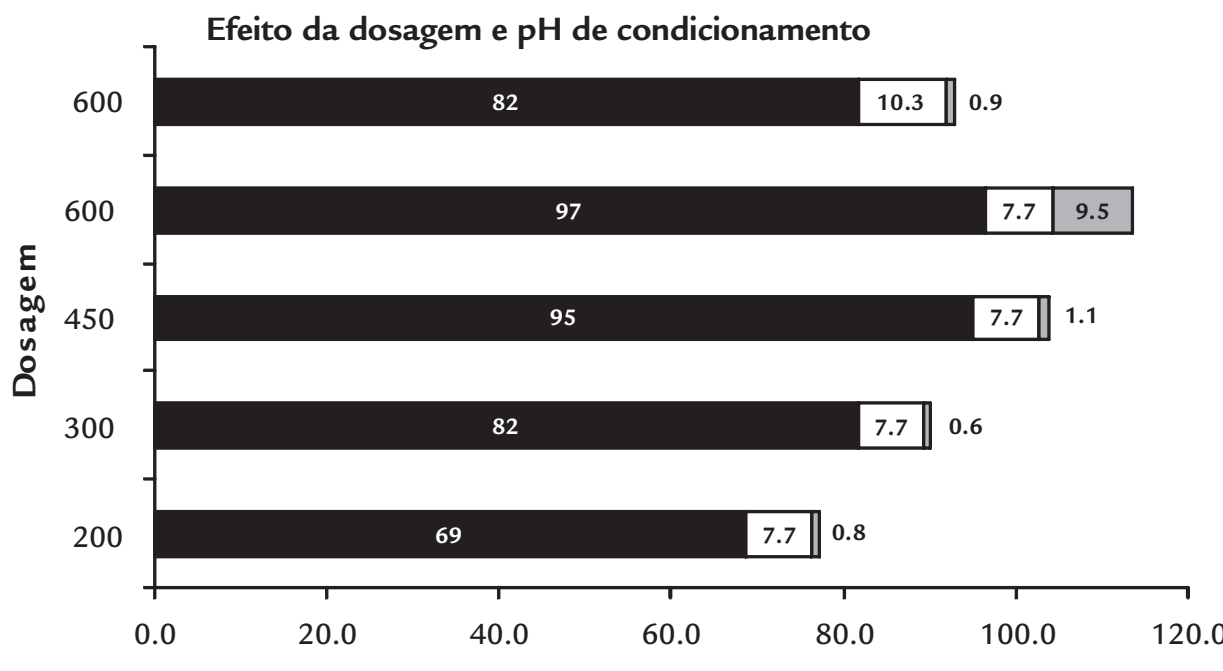

(\%)

Rec. Metálica $\square$ Teor de $\mathrm{SiO}$ no concentrado

\section{Conclusões}

Amostras de minerais de ferro que apresentaram maior conteúdo de hematitas compactas (HC) e menor tamanho de cristal apresentaram elevada afinidade pelo coletor, exigindo uma ação depressora mais eficiente com o intuito de minimizar sua tendência à flotação, reduzindo o teor de Fe no rejeito do processo. Comportamento distinto foi apresentado por amostras com menor percentual de HC e maior conteúdo de hematita martítica, magnetita e goethita, que não demanda- ram forte ação do agente depressor.

$\mathrm{O}$ amido de milho convencional se mostrou capaz de realizar ação depressora sobre todas as amostras de minerais de ferro, exceto as hematitas compactas. Estas últimas podem ser chamadas de "problemáticas", visto que interagem, fortemente, com o coletor e apresentam deficiência ao serem deprimidas pelo amido. Carboximetil celulose não apresentou ação depressora sobre nenhuma das amostras estudadas. mo a 8. Além disto, a dosagem necessária do amido modificado, para obtenção de elevados valores de recuperação metálica com teor de $\mathrm{SiO}_{2}$, no concentrado próximo a $1 \%$, foi inferior ao amido de milho condicionado em $\mathrm{pH}$ próximo a 10.
Figura 5

Efeito da dosagem de amido e $\mathrm{pH}$ de condicionamento. 


\section{Referências bibliográficas}

ARAUJO, A. C., VIANA, P. R. M., PERES, A. E. C. Reagents in iron ore flotation. Minerals Engineering, v. 18, p. 219-224, 2005.

BRANDÃO, P. R. G. A seletividade na flotação reversa de minério de ferro: adsorção dos reagentes. In: ENCONTRO NACIONAL DE TRATAMENTO DE MINÉRIOS E METALURGIA EXTRATIVA, 21. Anais... Natal: O2 Editora, 2005. v.1, p.22-33.

LASKOWSKI, J. The relationship between floatability and hydrophobicity. In: SOMASUNDARAN, P. (Ed.) Advances in mineral processing. Littleton: SME, 1986. Cap.11, p.189-208.

LEAL FILHO, L. S., RODRIGUES, W. J., LIMA, O. A., BARROS, L. A. F. The role of hydrodynamics in coarse apatite flotation. In: ZHANG, P. et al. (Eds). Beneficiation of phosphates: technology and sustainability. Littleton: SME, 2006. Cap. 3, p.25-36.

OLIVEIRA, J. F. Setor mineral: tendências tecnológicas. Texto elaborado para o projeto Setor Mineral - Tendências Tecnológicas, do Centro de Tecnologia Mineral - CETEM, 2006.

RAJU, B. G., HOLMGREN, A., FORSLING, W. Adsorption of dextrin at mineral/ water interface. Journal of Colloid and Interface Science, v. 193, p. 215-222, 1997.

RAJU, B. G., HOLMGREN, A., FORSLING, W. Complexation mechanism of dextrin with metal hydroxides. Journal of Colloid and Interface Science, v. 200, p. 1-6, 1998.

WHISTLER, R. L., PASCHALL, E. F. Starch:chemistry and technology. New York: Academic Press, 1965. v. 1. 579p.

Artigo recebido em 27 de junho de 2011. Aprovado em 14 de dezembro de 2011. 